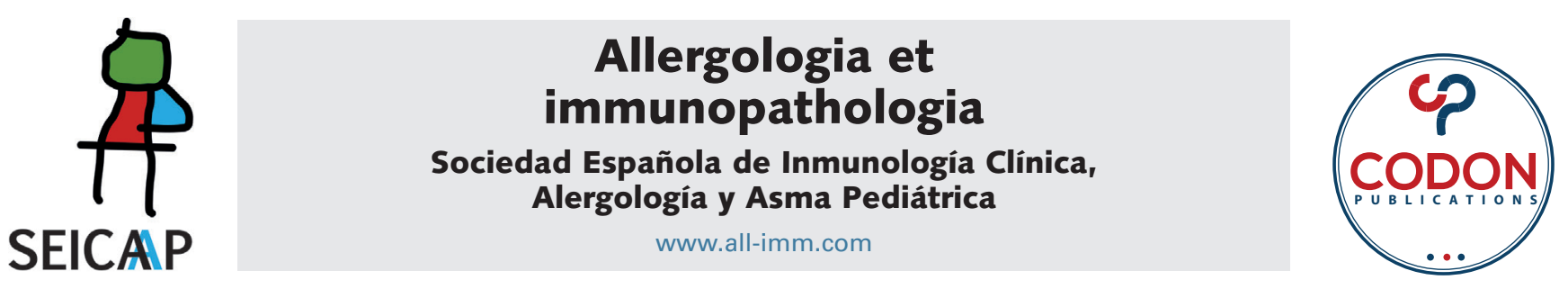

\title{
A novel homozygous RAG1 mutation is associated with severe combined immunodeficiency and neurological presentations
}

\author{
Melika Shafeghat ${ }^{\mathrm{a}, \mathrm{b}}$, Hossein Esmaeilzadeh ${ }^{\mathrm{c}, \mathrm{d} *}$, Mona Sadeghalvade, Elham Rayzana, \\ Samaneh Zoghib,g,h,i, Sepideh Shahkarami ${ }^{\mathrm{j}, \mathrm{k}}$, Raul Jimenez Heredia ${ }^{\mathrm{g}, \mathrm{h}, \mathrm{i}}$, Ana Krolo ${ }^{\mathrm{g}, \mathrm{h}, \mathrm{i}}$, \\ Kaan Boztug ${ }^{\mathrm{g}, \mathrm{h}, \mathrm{i}, \mathrm{m}}$, Nima Rezaej ${ }^{\mathrm{a}, \mathrm{b}, \mathrm{e}} \mathrm{k}$
}

\begin{abstract}
${ }^{a}$ Research Center for Immunodeficiencies, Children's Medical Center, Tehran University of Medical Sciences, Tehran, Iran ${ }^{b}$ Network of Immunity in Infection, Malignancy and Autoimmunity (NIIMA), Universal Scientific Education and Research Network (USERN), Tehran, Iran

'Allergy Research Center, Shiraz University of Medical Sciences, Shiraz, Iran

${ }^{d}$ Department of Allergy and Clinical Immunology, Namazi Hospital, Shiraz University of Medical Sciences, Shiraz, Iran

${ }^{e}$ Department of Immunology, School of Medicine, Tehran University of Medical Sciences, Tehran, Iran

fInternational Hematology/Oncology of Pediatrics Experts (IHOPE), Universal Scientific Education and Research Network (USERN),

Tehran, Iran

¿Ludwig Boltzmann Institute for Rare and Undiagnosed Diseases, Vienna, Austria

${ }^{h}$ CeMM Research Center for Molecular Medicine of the Austrian Academy of Sciences, Vienna, Austria

iSt. Anna Children's Cancer Research Institute (CCRI), Vienna, Austria

'Department of Pediatrics, Dr. Von Hauner Children's Hospital, Ludwig Maximilians University, Munich, Germany

${ }^{k}$ Medical Genetics Network (MeGeNe), Universal Scientific Education and Research Network (USERN), Munich, Germany

'Department of Pediatrics and Adolescent Medicine, Medical University of Vienna, Vienna, Austria

mSt. Anna Children's Hospital, Department of Pediatrics and Adolescent Medicine, Medical University of Vienna, Vienna, Austria
\end{abstract}

Received 25 August 2020; Accepted 15 December 2020

Available online 1 July 2021

\section{KEYWORDS \\ severe combined \\ immunodeficiency; \\ SCID; \\ recombination \\ activating gene; \\ RAG1; targeted \\ sequencing; \\ NGS}

\begin{abstract}
Introduction and objectives: Severe combined immunodeficiency (SCID) is a subset of primary immunodeficiency diseases caused by a hereditary deficiency of the adaptive immune system. Mutation in recombination activating gene $(R A G)$ is known as the underlying genetic cause of SCID. RAG protein plays a pivotal role in $\mathrm{V}(\mathrm{D}) \mathrm{J}$ recombination which is the main process to assemble lymphocyte antigen receptors during $\mathrm{T}$ - and B-cell development. The patients are characterized by recurrent infections, failure to thrive, chronic diarrhea, and fever, in early infancy. Herein, we present a case of SCID with rare neurological manifestations affected by a mutation in RAG1. Patients and methods: The patient was a 15-month-old infant born to a consanguineous family. She was presented with neurological abnormalities including facial nerve palsy, seizure,
\end{abstract}

*Corresponding authors: Nima Rezaei, MD, PhD. Research Center for Immunodeficiencies, Children's Medical Center Hospital, Dr. Qarib St, Keshavarz Blvd, Tehran 14194, Iran. E-mail address: rezaei_nima@tums.ac.ir; and Hossein Esmaeilzadeh, MD. Department of Allergy and Clinical Immunology, Namazi Hospital, Shiraz University of Medical Sciences, Imam Hussain Square, Zand St., Shiraz 7134845794, Iran. E-mail address: esmailzadeh_ho@yahoo.com. 
and decreased consciousness. Next-generation sequencing (NGS)-based primary immunodeficiency disease (PID)-gene panel screen and Sanger sequencing were performed to identify the genetic mutation.

Results: We found a novel homozygous missense mutation in RAG1, c.1210C >T,p.Arg404Trp, which was predicted to be deleterious (combined annotation dependent depletion, CADD score of 27.4). Both parents were heterozygous carriers for this mutation. According to her laboratory data, both $\mathrm{T}$ cell and $\mathrm{B}$ cell numbers were decreased and the patient was diagnosed as RAG1- SCID.

Conclusions: SCID is a pediatric emergency with a variety of manifestations in infants. Therefore, accurate diagnosis importantly in the case of rare manifestations must be considered in these patients. Our findings point toward the importance of genetic assessment for early diagnosis and timely treatment of this disorder.

(c) 2021 Codon Publications. Published by Codon Publications.

\section{Introduction}

Severe combined immunodeficiency (SCID), is a hereditary group of disorders with the highest rate of mortality between the inborn errors of immunity (IEI). ${ }^{1}$ The incidence of the disease is one in 40,000 to 75,000 newborns. ${ }^{2}$ Both cellular and humoral immune systems can be involved in SCID. The patients suffer from either a very low number of T-cells or decreased function of these cells (CD3+, $\mathrm{CD} 4+$, and $\mathrm{CD} 8+$ ) with or without a reduction in the number of B lymphocytes (CD19+, CD20+) and/or even natural killer cells (CD16+, CD56+). ${ }^{3}$ Hence, SCID is classified into four sub-groups with regard to the lack or presence of $T$, $B$, and natural killer cells (NK) including T-B-NK-, T-B-NK+, $\mathrm{T}-\mathrm{B}+\mathrm{NK}+$, and $\mathrm{T}-\mathrm{B}+\mathrm{NK}-.^{4}$

The primary clinical manifestations frequently present between 4 and 7 months of age including chronic diarrhea, insufficient growth, and recurrent infections. ${ }^{5}$ The neurodevelopmental defects are not common and progressive in SCID patients, nevertheless, seizure and microcephaly have been observed in some cases. ${ }^{6}$ Moreover, infants who suffer from SCID are more vulnerable to be infected with community-acquired infections that lead to end-organ dysfunction. Such infections might affect multiple organs like the lungs and liver which makes SCID a pediatrics' emergency. ${ }^{7}$

Genetic mutations in SCID patients are divided into X-linked and autosomal recessive forms. ${ }^{8}$ To date, multiple known mutations have been reported which are associated with different types of SCID including recombination activating gene 1 (RAG1), RAG2, interleukin 2 receptor gamma (IL2RG), adenosine deaminase (ADA), purine nucleoside phosphorylase (PNP), etc. Except for IL2RG mutation with $\mathrm{X}$-linked inheritance, other mutations are autosomal recessive. ${ }^{9,10}$

Mutations in RAG1 and RAG2 are the most common causative gene in countries where a high rate of consanguinity is known. ${ }^{11-13}$ RAG1 encodes proteins that are involved in DNA breakage and repair during rearrangement of the genes encoding the variable (V), diversity (D), and joining $(\mathrm{J})$ segments. This process leads to provide a variety of antigen recognition sites for $T$ and $B$ cell receptors..$^{14,15}$

The phenotypic spectrum of primary immunodeficiency (PID) associated with RAG1 mutations differs depending on the nature of the defect, and its impact on $V(D) J$ recombination. Amorphic or null mutations of both alleles of $R A G 1$ result in complete RAG1 deficiency leading to a severe combined immunodeficiency phenotype which is characterized by a lack of $\mathrm{T}$ and $\mathrm{B}$ lymphocytes. ${ }^{16,17}$ The patients with this phenotype exhibit recurrent infections and failure to thrive (FTT) in early infancy. ${ }^{18-20}$ Hypomorphic RAG1 mutations result in very low levels of recombination activity characterized by residual development of $T$ and B lymphocytes. Different phenotypes associated with hypomorphic mutations are including Omenn syndrome characterized by hepatosplenomegaly, lymphadenopathy, eosinophilia, elevated IgE levels in serum, and erythroderma ${ }^{21-23}$; atypical Omenn syndrome characterized by skin inflammation without T-cell expansion, more than 3\% B-cells, a low frequency of CD31 cells, ${ }^{24}$ and atypical SCID with $\gamma \delta$ T-cell expansion characterized by autoimmunity, severe cytomegalovirus infection, and partially functioning B-cells with a limited ability for antibody production. ${ }^{25-27}$

Therefore, the mutation of this gene could affect the immune system due to the impaired development of lymphocytes. ${ }^{28}$ Timely genetic assessment and implementation of appropriate therapies could improve symptoms and decrease morbidity in these patients. Herein, we for the first time describe an Iranian case of SCID with neurological manifestations affected by a novel homozygous mutation in RAG1 which resulted in TlowB-NK+ type of SCID.

\section{Patients and Methods}

\section{Case presentation}

A 15-month-old female was admitted to Namazi Hospital of Shiraz University of Medical Sciences with decreased vital signs, cyanosis, seizure, poor feeding, and right facial nerve palsy. Her parents were first cousins and there was a history of fatality in her parents' family because of the several cancers as well as congenital palsy in childhood (Figure 1a). The patient has no siblings and her mother had one miscarriage due to unknown causes. The patient's maternal grandmother has experienced repetitive abortions of unknown etiology. Her uncle passed away in infancy due to unknown causes. Besides, two grandchildren of the patient's maternal aunt passed away in childhood because 
(A)

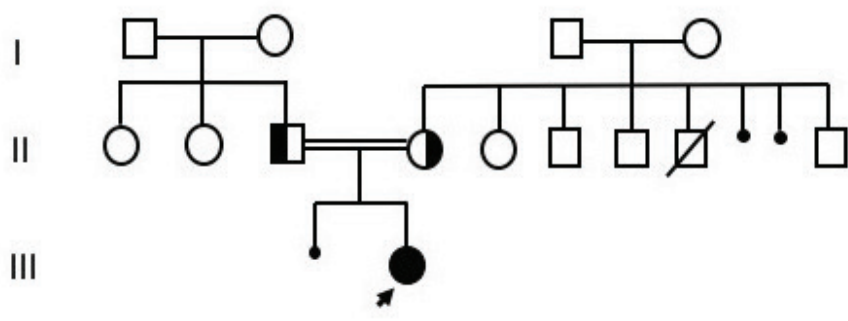

(B)

Patient

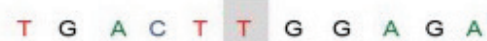

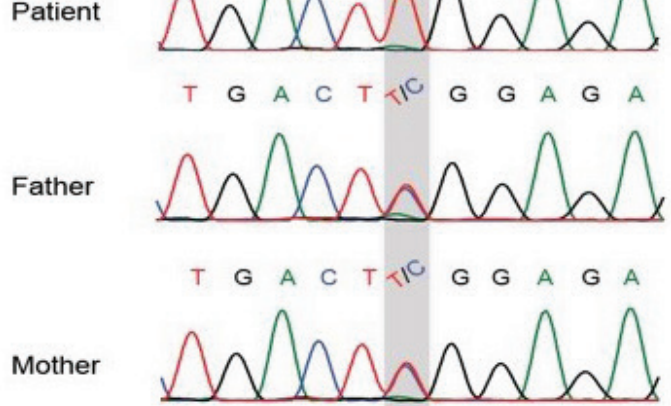

Figure 1 (A) Pedigree of the patient. The patient was homozygous for c.1210C>T,p.Arg404Trp mutation and is shown by a solid black symbol. (B) Sanger sequencing of the patient and her parents. A homozygous and heterozygous missense mutation in RAG1, c.1210C > T,p.Arg404Trp, was shown in the patient and both parents, respectively.

of blood cancer and congenital palsy. Also, the patient's paternal aunt and cousin passed away due to an unknown type of cancer.

She had a history of hospitalization at the age of 6 months (April 2018) due to the diagnosis of BCGitis with axillary and supraclavicular lymphadenopathies along with purulent secretion. Her blood sample was positive for acidfast bacilli (AFB) and tuberculosis (TB) culture. Additionally, she had pustular lesions around her anus leading to necrosis. She received antibiotics, antifungal, and antiviral drugs (Figure 2).

At the time of second admission (Dec 2018), general examinations showed normal chest, HEENT evaluation (head, ears, eyes, nose, and throat), abdominal, and extremity exam. Abdomen and pelvic sonography appeared normal. The patient suffered from lethargic mental status during the first days of administration. Also, the patient experienced a partial seizure with loss of consciousness afterward. She was intubated and admitted to the neurology ward to receive antiepileptic medicine including Topiramate, Levetiracetam, Phenytoin, Phenobarbital, and Clobazam for status epilepticus. Besides, she received broad-spectrum antibiotics and antifungal drugs (Figure 2).

The result of the electroencephalogram showed Status Epilepticus due to refractory complete partial seizure. The Brain CT scan was normal. There were no signs of increased intracranial pressure and no abnormalities in the cerebellopontine angle areas on both sides and the calvarium.

The echocardiography result was normal and no pulmonary hypertension was observed. The result for brain MRI disclosed evidence of T1 increase intensity in both basal ganglia that is suggestive for early calcification or anoxia damage due to the postictal phase of the seizure. Otherwise, there was no sign of mass or hemorrhage or ischemic infarction within the brain parenchyma. No hydrocephalus or shift of midline structures was seen. 7th-8th nerve root complexes appeared normal. The pituitary gland was unremarkable. No extra-axial mass or hematoma or fluid collection was seen. We did not receive any shreds of evidence for T2-weighted images. Besides, the primitive electrocardiogram was abnormal with low voltage evidence.

Laboratory investigations including complete blood count $(C B C)$, immunoglobulin levels, flow-cytometry for immunophenotyping, Dihydrorhodamine test (DHR), cerebrospinal fluid (CSF) analysis including polymerase chain reaction (PCR) for herpes simplex virus (HSV), and CSF culture were performed. Besides, next-generation sequencing (NGS)-based PID-gene panel screen, which targets $>500$ genes in parallel, and Sanger sequencing were requested to investigate gene mutations.

The patient had an uncontrolled seizure and had to be intubated. She fell into a coma and vegetative state

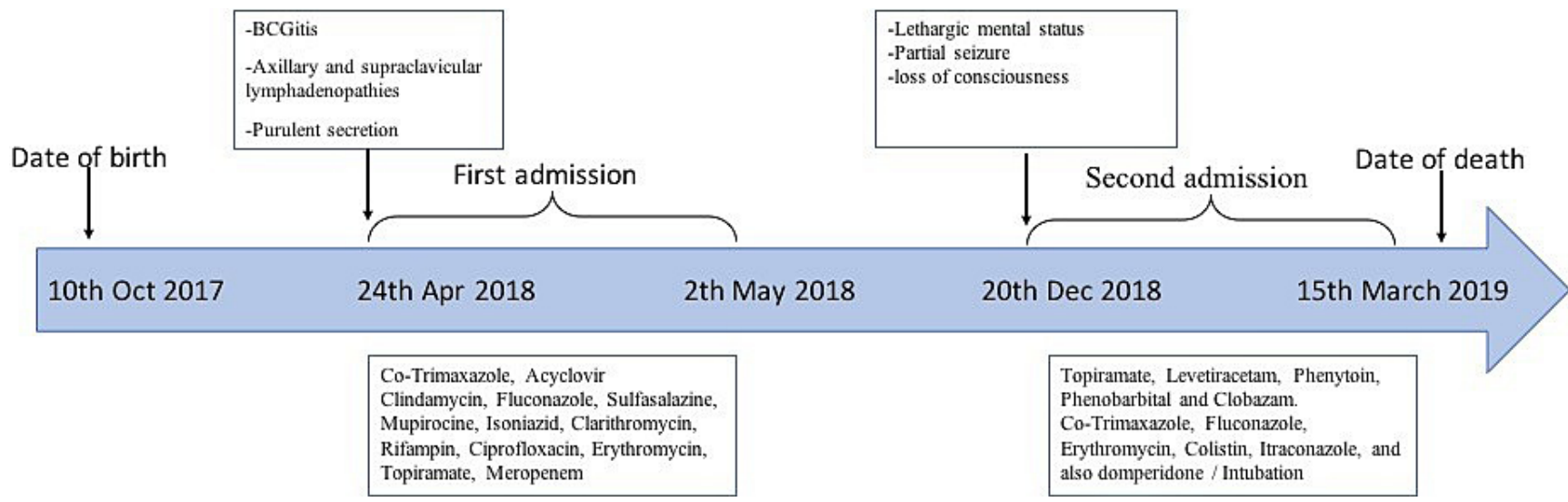

Figure 2 Timeline graph depicting the patient's clinical course and treatments. 
after administering anesthesia for a tracheostomy. Then, she was under the mechanical ventilator in the neurology ward. Unfortunately, 3 months after hospitalization she passed away due to persistent seizures and cardiopulmonary arrest.

\section{Results}

The laboratory results are summarized in Tables 1 and 2 . Immunophenotyping using flow-cytometry showed decreased levels of both T- and B-cell markers including CD3, CD4, CD8, CD19, and CD20. Moreover, the markers for NK cells including CD16 and CD56, CD14 for monocytes, CD11b, and interferon-gamma receptor were normal. The DHR test was also within the normal range $(220$, normal $>50$ ). Hypogammaglobulinemia and lymphopenia were detected in the evaluation of immunoglobulin levels and $\mathrm{CBC}$ results, respectively. No CNS infection was documented. PCR HSV and CSF culture were negative. CSF findings are shown in Table 2.

NGS and Sanger sequencing results of our patient showed a novel homozygous missense mutation in RAG1 (NM_000448.3:c.1210C>T, p.Arg404Trp) that was predicted to be deleterious (CADD score of 27.4). ${ }^{29}$ Both parents were heterozygous carriers for this mutation (Figure $1 \mathrm{~b}$ ).

\section{Discussion}

RAG1 and RAG2 are known as the most common underlying genetic cause of SCID. These genes are restricted to lymphocytes and encode the proteins involved in gene rearrangement and site-specific $V(D) J$ recombination of the lymphocyte receptor. Thereby, the mutations in RAG can result in a lack or reduced levels of lymphocytes or producing immature lymphocytes with impaired function. T negative (-) B negative (-) NK positive $(+)$ phenotype is the frequent type of SCID caused by RAG mutation and counts for about 20 percent of all SCID cases. ${ }^{10}$

Table 1 CBC results of the patient.

\begin{tabular}{lcccc}
\hline & \multicolumn{3}{c}{ Patient } & \\
\cline { 2 - 4 } & Jan. & Feb. & March. & Normal \\
& 2019 & 2019 & 2019 & range \\
\hline WBC (mm $\left.{ }^{3}\right)$ & 6000 & 10,900 & 5600 & $3100-21,600$ \\
Neut & 3660 & 6649 & 3752 & $4940-7410$ \\
Lymph & 600 & 654 & 280 & $2470-4940$ \\
Eos & 240 & 327 & 224 & $123-494$ \\
RBC (*10 $12 / L)$ & 3.85 & 3.53 & 3.4 & $3.12-7.3$ \\
Hb (g/dL) & 10.9 & 10.6 & 9.5 & $11-17.3$ \\
HCT (\%) & 31.4 & 29.5 & 29.1 & $35.4-56.5$ \\
MCV (fL) & 81.6 & 83.6 & 85.4 & $90.4-128$ \\
MCH (pg) & 28.3 & 30 & 28.2 & $34.41-2.36$ \\
Plat (*10\%/L) & 93 & 401 & 268 & $152-472$ \\
\hline WBC: white blood
\end{tabular}

WBC: white blood cells; Neu: neutrophils; Lymph: lymphocyte; Eos: eosinophils; RBC: red blood cells; Hb: hemoglobin; HCT: hematocrit; MCV: mean cell volume; $\mathrm{MCH}$ : mean corpuscular hemoglobin; Plat: platelet.
Table 2 Summary of laboratory evaluation.

\begin{tabular}{|c|c|c|c|}
\hline Blood & \multicolumn{3}{|l|}{ Result } \\
\hline Culture & \multicolumn{3}{|c|}{$\begin{array}{r}\text { Pseudomonas } \\
\text { aeruginosa }\end{array}$} \\
\hline $\mathrm{CSF}^{*}$ & \multicolumn{3}{|l|}{ Result } \\
\hline RBC & \multicolumn{3}{|l|}{ Negative } \\
\hline WBC & \multicolumn{3}{|l|}{ Negative } \\
\hline Sugar (mg/dL) & \multicolumn{3}{|l|}{61} \\
\hline Protein (mg/dL) & \multicolumn{3}{|l|}{18} \\
\hline Culture & \multicolumn{3}{|l|}{ Negative } \\
\hline HSV (PCR) & \multicolumn{3}{|l|}{ Negative } \\
\hline Immunoglobulins & \multicolumn{2}{|l|}{ Result } & Normal range \\
\hline IgG (mg/dL) & \multicolumn{2}{|l|}{13.8} & $200-1000$ \\
\hline IgM (mg/dL) & \multicolumn{2}{|l|}{1.66} & $25-150$ \\
\hline IgA (mg/dL) & \multicolumn{2}{|l|}{3.47} & $4-90$ \\
\hline $\lg E(I U / m L)$ & \multicolumn{2}{|l|}{80} & $<200$ \\
\hline $\begin{array}{l}\text { Blood Flow } \\
\text { cytometry } \\
\text { analysis: } \\
\text { lymphocytes } \\
\text { subsets } / \mathrm{mm}^{3}(\%)\end{array}$ & $\begin{array}{l}\text { Apr, } \\
2018\end{array}$ & $\begin{array}{l}\text { July, } \\
2018\end{array}$ & $\begin{array}{l}\text { Normal } \\
\text { range }\end{array}$ \\
\hline CD3 & $795(38)$ & $334(16)$ & $\begin{array}{c}1852-2853 \\
(50-77)\end{array}$ \\
\hline CD4 & $544(26)$ & $188(9)$ & $\begin{array}{c}1222-2149 \\
(33-58)\end{array}$ \\
\hline CD8 & $146(7)$ & $83(4)$ & $\begin{array}{r}482-963 \\
(13-26)\end{array}$ \\
\hline CD19 & $42(2)$ & $20(1)$ & $\begin{array}{r}482-1297 \\
(13-35)\end{array}$ \\
\hline CD20 & $21(1)$ & $20(1)$ & $\begin{array}{r}482-1297 \\
(13-35)\end{array}$ \\
\hline CD16 & $1255(60)$ & $1737(83)$ & $74-482(2-13)$ \\
\hline CD56 & $1255(60)$ & $1737(83)$ & $74-482(2-13)$ \\
\hline CD14 & $272(13)$ & N/A & $111-222(3-6)$ \\
\hline
\end{tabular}

*CSF: cerebrospinal fluid; Ig: Immunoglobulin; N/A: not available.

Here, we identified a novel mutation in the RAG1 gene (c.1210C > T, p.Arg404Trp) for which the child was homozygous and both parents were found to be heterozygous. Our patient was presented with FTT and rare neurological manifestations including nerve palsy, loss of consciousness, and persistent seizures since the age of 15 months. The patient developed recurrent infections and BCGitis in early infancy that could dictate early investigation regarding the possibility of primary immunodeficiency.

A heterozygous mutation in this position (RAG1, p.Arg404Trp) has been previously reported in a patient with T-B-NK+ Omenn syndrome. Corneo et al., reported a 2.5 months old boy with early onset of diffuse erythroderma, eosinophilia, diarrhea, and FTT. His laboratory findings have been shown a decreased level of lymphocytes and CD3, lack of CD19, and normal NK cells. ${ }^{30}$ Our patient had lymphadenopathy and suspicious lesions around her anus and Omenn syndrome could be a probable consideration for this case. Since she had neither hepatosplenomegaly 
nor eosinophilia in the peripheral smear, the possibility of Omenn syndrome was ruled out.

Regarding the other types of SCID, X-linked SCID and Janus kinase 3 (Jak3) deficiency were ruled out. These disorders are determined by an elevated number of B-cells while our patients had reduced levels of B-cells. Besides, in adenosine deaminase ( $A D A)$-deficient SCID, bone abnormalities presentations are more frequent, which were absent in this case. ${ }^{30}$

Neurological presentations and facial nerve palsy occurred in our case are uncommon presentations of SCID patients. Neurological presentations in the patients with RAG1 mutation except for a limited number have not yet been reported. Dhingra et al., ${ }^{31}$ described a 15-month-old boy with RAG1-SCID who had progressive encephalopathy and partial seizures. His immunological evaluation showed hypogammaglobulinemia, T- and B-cells lymphopenia, and normal NK cells. His genetic investigations revealed a homozygous mutation in RAG1 (c:2881T>C; p:I794T). In accordance with this, the immunophenotyping results and immunoglobulin levels of our patient showed a decreased level of T- and B-cells, normal NK cells, and hypogammaglobulinemia, and the patient was suspected to have TlowB-NK+ SCID.

In addition, some of the neurological abnormalities in SCID have been described in ADA deficiency, DNA ligase IV deficiency, and Cernunnos deficiency. Neurological manifestations in ADA-deficient SCID are including mental retardation, seizure, behavioral abnormalities, motor delay, and nystagmus that might be related to toxic accumulation of adenosine in the brain. ${ }^{32-34}$ Microcephaly and developmental delay were recognized in DNA ligase IV deficiency and Cernunnos deficiency patients. ${ }^{32,33,35}$

There is not enough evidence to explain the relation between RAG deficiency and neurological presentation. It has been shown that the RAG1 gene is expressed in the central nervous system, especially in the brain of vertebrates and the transcription of RAG1 initiates as soon as the neural stages of development. Hence, RAG1 protein could play an important role in the central nervous system development. ${ }^{36}$ Although RAG1 expression has been found in the central nervous system of the mouse, no apparent neuroanatomical or behavioral abnormalities have been detected in the RAG1-deficient mice. ${ }^{37}$ We believe further investigation about the expression of RAG1 in neurological tissues might be helpful.

On the other hand, we cannot rule out the possible role of autoreactive antibodies or T-cells in SCID patients. SCID could be associated with autoimmune disorders, usually in the Omenn's syndrome phenotype. It has been shown that central tolerance that is responsible for the elimination of autoreactive T-cell clones, has a defect in SCID. Besides, peripheral tolerance is reduced in SCID due to several factors such as the expansion of T-cell clones in charge of the consequence of the lymphopenia as well as $T$ regulatory (FOXP3+) cell numbers reduction, which all allowing autoreactive $\mathrm{T}$-cells to proliferate and infiltrate various organs in the body of patients with SCID. It is thus of no surprise when both central and peripheral tolerance is impaired that autoimmunity can be observed in SCID. ${ }^{38}$
Although these findings indicate the autoimmunity and autoreactive T-cells might appear in SCID as in our case, the role of autoimmunity in CNS is not yet proven.

On the other hand, since CNS infections have been reported in some SCID patients, the possibility of CNS infection in these patients should not be ignored. Waruiru et al., ${ }^{39}$ described eight patients of SCID including patients with RAG deficiency and T-B- NK+ SCID with CNS viral infections confirmed by PCR. The CSF analysis in our case was completely normal.

We present this RAG1-deficient patient with rare neurological presentations to hallmark the significant role of early genetic analysis. Timely genetic assessment in patients with the same clinical presentations could be important in early diagnosis and implement appropriate therapy to manage the severe outcomes.

Hematopoietic stem cell transplantation (HSCT) can be an efficient and permanent cure for children with RAG1SCID. ${ }^{40,41}$ Although HSCT is considered a life-saving treatment, it could be limited due to the obstacles such as high rates of graft versus host disease (GVHD) and transplant-related mortality. ${ }^{42}$ Gene therapy is shown to be successful in treating patients with X-linked SCID and ADA-SCID. ${ }^{43-48}$ As there are some hopeful results obtained from the pre-clinical phase, this approach might receive the attention of researchers for treating the patients with RAG1-SCID in future studies. ${ }^{49,50}$

\section{Authors' contributions}

All authors have been contributed significantly to the work, have read the manuscript, attest to the validity, and agree to its submission.

\section{Conflicts of interest}

The authors have no conflicts of interest to declare.

\section{Ethical disclosure}

After describing the novelty of the genomic mutation causing the disease for the patient's family, they orally consented to the authors to use the patient's medical records for publication.

\section{References}

1. Shen J, Gao Y, Yu S, Wu C. A novel RAG1 mutation in a compound heterozygous status in a child with Omenn syndrome. Front Genet. 2019;10:913. https://doi.org/10.3389/ fgene.2019.00913

2. Cossu F. Genetics of SCID. Ital J Pediatr. 2010;36(1):76. https:// doi.org/10.1186/1824-7288-36-76

3. Pourvali A, Arshi S, Nabavi M, Bemanian MH, Shokri S, Shahrooei $M$, et al. Atypical Omenn syndrome due to RAG2 gene mutation: a case report. Iran J Immunol. 2019;16(4):334338. https://doi.org/10.22034/IJI.2019.80285 
4. Picard C, Al-Herz W, Bousfiha A, Casanova J-L, Chatila T, Conley ME, et al. Primary immunodeficiency diseases: an update on the classification from the International Union of Immunological Societies Expert Committee for Primary Immunodeficiency 2015. J Clin Immunol. 2015;35(8):696-726. https://doi.org/10.1007/s10875-015-0201-1

5. Ogando JCB, Gaytán AP, Becerra JCA, Cardona AÁ, Bezrodnik L, Borzutzky A, et al. Latin American consensus on the supportive management of patients with severe combined immunodeficiency. J Allergy Clin Immunol. 2019;144(4):897905. https://doi.org/10.1016/j.jaci.2019.08.002

6. Woodbine L, Neal JA, Sasi N-K, Shimada M, Deem K, Coleman $\mathrm{H}$, et al. PRKDC mutations in a SCID patient with profound neurological abnormalities. J Clin Invest. 2013;123(7):2969-2980. https://doi.org/10.1172/JCl67349

7. Gennery A, Cant A. Diagnosis of severe combined immunodeficiency. J Clin Pathol. 2001;54(3):191-195. https://doi. org/10.1136/jcp.54.3.191

8. Puck JM, Pepper AE, Henthorn PS, Candotti F, Isakov J, Whitwam T, et al. Mutation analysis of IL2RG in human X-linked severe combined immunodeficiency. Blood. 1997;89(6):19681977. PMID: 9058718

9. Kalman L, Lindegren ML, Kobrynski L, Vogt R, Hannon $H$, Howard JT, et al. Mutations in genes required for T-cell development: IL7R, CD45, IL2RG, JAK3, RAG1, RAG2, ARTEMIS, and ADA and severe combined immunodeficiency: HuGE review. Genet Med. 2004;6(1):16-26. https://doi.org/10.1097/01. GIM.0000105752.80592.A3

10. Tangye SG, Al-Herz W, Bousfiha A, Chatila T, CunninghamRundles C, Etzioni A, et al. Human inborn errors of immunity: 2019 update on the classification from the International Union of Immunological Societies Expert Committee. J Clin Immunol. 2020;40(1):24-64. https://doi org/10.1007/s10875-020-00763-0; https://doi.org/10.1007/ s10875-019-00737-x

11. Shahbazi Z, Yazdani R, Shahkarami S, Shahbazi S, Hamid M, Sadeghi-Shabestari $M$, et al. Genetic mutations and immunological features of severe combined immunodeficiency patients in Iran. Immunol Lett. 2019;216:70-78. https://doi. org/10.1016/j.imlet.2019.10.001

12. Parvaneh N, Casanova J-L, Notarangelo LD, Conley ME. Primary immunodeficiencies: a rapidly evolving story. J Allergy Clin Immunol. 2013;131(2):314-323. https://doi.org/10.1016/ j.jaci.2012.11.051

13. Safaei S, Pourpak Z, Moin M, Houshmand M. IL7R and RAG1/2 genes mutations/polymorphisms in patients SCID. Iran J Allergy Asthma Immunol. 2011;10(2):129-132. PMID: 21625022

14. Hesslein DG, Schatz DG. Factors and forces controlling $\vee(D)$ J recombination. Adv Immunol. 2001;78:169-232. https://doi. org/10.1016/S0065-2776(01)78004-2

15. Gellert M. V (D) J recombination: RAG proteins, repair factors, and regulation. Annu Rev Biochem. 2002;71(1):101-132. https://doi.org/10.1146/annurev.biochem.71.090501.150203

16. Buckley RH, Schiff RI, Schiff SE, Markert ML, Williams LW, Harville TO, et al. Human severe combined immunodeficiency: genetic, phenotypic, and functional diversity in one hundred eight infants. J Pediatr. 1997;130(3):378-387. https:// doi.org/10.1016/S0022-3476(97)70199-9

17. van Der Burg $M$, Weemaes $C$, Preijers $F$, Brons $P$, Barendregt $\mathrm{BH}$, van Tol $\mathrm{M}$, et al. B-cell recovery after stem cell transplantation of Artemis-deficient SCID requires elimination of autologous bone marrow precursor-B-cells. Haematologica. 2006;91(12):1705-1709. PMID: 17145611

18. Sobacchi C, Marrella V, Rucci F, Vezzoni P, Villa A. RAG-dependent primary immunodeficiencies. Human Mutation. 2006;27(12):1174-1184. https://doi.org/10.1002/humu.20408

19. Asai E, Wada T, Sakakibara Y, Toga A, Toma T, Shimizu T, et al. Analysis of mutations and recombination activity in
RAG-deficient patients. Clin Immunol. 2011;138(2):172-177. https://doi.org/10.1016/j.clim.2010.11.005

20. Barthels C, Puchatka J, Racek T, Klein C, Brocker T. Novel spontaneous deletion of Artemis exons 10 and 11 in mice leads to T-and B-cell deficiency. PLoS One. 2013;8(9):e74838. https://doi.org/10.1371/journal.pone.0074838

21. Hönig M, Schwarz K. Omenn syndrome: a lack of tolerance on the background of deficient lymphocyte development and maturation. Curr Opin Rheumatol. 2006;18(4):383-388. https://doi.org/10.1097/01.bor.0000231907.50290.6f

22. Villa A, Notarangelo LD, Roifman CM. Omenn syndrome: inflammation in leaky severe combined immunodeficiency. J Allergy Clin. Immunol. 2008;122(6):1082-1086. https://doi. org/10.1016/j.jaci.2008.09.037

23. Santagata S, Villa A, Sobacchi C, Cortes P, Vezzoni P. The genetic and biochemical basis of Omenn syndrome. Immunol Rev. 2000;178:64-74. https://doi.org/10.1034/ j.1600-065X.2000.17818.x

24. Villa A, Sobacchi C, Notarangelo LD, Bozzi F, Abinun M, Abrahamsen TG, et al. $V$ (D) J recombination defects in lymphocytes due to RAG mutations: severe immunodeficiency with a spectrum of clinical presentations. Blood. 2001;97(1):81-88. https://doi.org/10.1182/blood.V97.1.81

25. de Villartay J-P, Lim A, Al-Mousa H, Dupont S, DéchanetMerville J, Coumau-Gatbois E, et al. A novel immunodeficiency associated with hypomorphic RAG1 mutations and CMV infection. J Clin Invest. 2005;115(11):3291-3299. https://doi. org/10.1172/JCI25178

26. Ehl S, Schwarz K, Enders A, Duffner U, Pannicke U, Kühr J, et al. A variant of SCID with specific immune responses and predominance of $\gamma \delta$ T cells. J Clin Invest. 2005;115(11):3140-3148. https://doi.org/10.1172/JCI25221

27. Karaca NE, Aksu G, Genel F, Gulez N, Can S, Aydinok Y, et al. Diverse phenotypic and genotypic presentation of RAG1 mutations in two cases with SCID. Clin Exp Med. 2009;9(4):339. https://doi.org/10.1007/s10238-009-0053-1

28. Carmona LM, Schatz DG. New insights into the evolutionary origins of the recombination-activating gene proteins and $\mathrm{V}$ (D) J recombination. FEBS J. 2017;284(11):1590-1605. https:// doi.org/10.1111/febs.13990

29. Kircher M, Witten DM, Jain P, O’Roak BJ, Cooper GM, Shendure J. A general framework for estimating the relative pathogenicity of human genetic variants. Nature Genet. 2014;46(3):310-315. https://doi.org/10.1038/ng.2892

30. Corneo B, Moshous D, Gungor T, Wulffraat N, Philippet P, et al. Identical mutations in RAG1 or RAG2 genes leading to defective $V(D) J$ recombinase activity can cause either T-B-severe combined immune deficiency or Omenn syndrome. Blood. 2001;97:2772-2776. https://doi.org/10.1182/blood.V97.9.2772

31. Dhingra N, Yadav SP, de Villartay J-P, Picard C, Sabharwal R, Dinand V, et al. Severe combined immunodeficiency caused by a new homozygous RAG1 mutation with progressive encephalopathy. Hematol Oncol Stem Cell Ther. 2014;7(1):44-49. https://doi.org/10.1016/j.hemonc.2013.11.001

32. Aydin ÖF, Anlar B. Neurological manifestations of primary immunodeficiency diseases. Clin Pediatr. 2018;57(7):761-774. https://doi.org/10.1177/0009922817737083

33. Dehkordy SF, Aghamohammadi A, Ochs HD, Rezaei N. Primary immunodeficiency diseases associated with neurologic manifestations. J Clin Immunol. 2012;32(1):1-24. https://doi. org/10.1007/s10875-011-9593-8

34. Nofech-Mozes Y, Roifman C. Neurological manifestations in severe combined immunodeficiency secondary to adenosine deaminase deficiency: three case reports and review of the literature. J Allergy Clin Immunol. 2005;115(2):S78. https:// doi.org/10.1016/j.jaci.2004.12.325

35. Enders A, Fisch P, Schwarz K, Duffner U, Pannicke U, Nikolopoulos E, et al. A severe form of human combined 
immunodeficiency due to mutations in DNA ligase IV. J Immunol. 2006;176(8):5060-5068. https://doi.org/10.4049/ jimmunol.176.8.5060

36. Frippiat C, Kremarik P, Ropars A, Dournon C, Frippiat J-P. The recombination-activating gene 1 of Pleurodeles walt (urodele amphibian) is transcribed in lymphoid tissues and in the central nervous system. Immunogenetics. 2001;52(3-4):264-275. https://doi.org/10.1007/s002510000275

37. Mombaerts P, lacomini J, Johnson RS, Herrup K, Tonegawa S, Papaioannou VE. RAG-1-deficient mice have no mature $B$ and T lymphocytes. Cell. 1992;68(5):869-877. https://doi. org/10.1016/0092-8674(92)90030-G

38. Milner JD, Fasth A, Etzioni A. Autoimmunity in severe combined immunodeficiency (SCID): lessons from patients and experimental models. J Clin Immunol. 2008;28(1):29. https:// doi.org/10.1007/s10875-007-9159-y

39. Waruiru C, Slatter MA, Taylor C, Ramesh V, Flood TJ, Abinun M, et al. Outcome of hematopoietic stem cell transplantation in severe combined immune deficiency with central nervous system viral infection. Pediatr Infect Dis J. 2007;26(2):129-133. https://doi.org/10.1097/01.inf.0000250621.46742.b5

40. Buckley RH. Transplantation of hematopoietic stem cells in human severe combined immunodeficiency: longterm outcomes. Immunol Res. 2011;49(1-3):25-43. https://doi.org/10.1007/s12026-010-8191-9

41. Castagnoli R, Delmonte OM, Calzoni E, Notarangelo LD. Hematopoietic stem cell transplantation in primary immunodeficiency diseases: current status and future perspectives. Front Pediatr. 2019;7:295. https://doi.org/10.3389/ fped.2019.00295

42. Vertès AA. The potential of cytotherapeutics in hematologic reconstitution and in the treatment and prophylaxis of graftversus-host disease. Chapter I: current practice and remaining unmet medical needs. Regen Med. 2015;10(3):331-343. https://doi.org/10.2217/rme.15.12
43. Cavazzana-Calvo M, Fischer A. Gene therapy for severe combined immunodeficiency: Are we there yet? J Clin Invest. 2007;117(6):1456-1465. https://doi.org/10.1172/JCI30953

44. Gaspar HB, Thrasher AJ. Gene therapy for severe combined immunodeficiencies. Expert Opin Biol Ther. 2005;5(9):11751182. https://doi.org/10.1517/14712598.5.9.1175

45. Aiuti A. Advances in gene therapy for ADA-deficient SCID. Curr Opin Mol Ther. 2002;4(5):515-522. PMID: 12435054

46. Aiuti A, Cassani B, Andolfi G, Mirolo M, Biasco L, Recchia A, et al. Multilineage hematopoietic reconstitution without clonal selection in ADA-SCID patients treated with stem cell gene therapy. J Clin Invest. 2007;117(8):2233-2240. https:// doi.org/10.1172/JCl31666

47. Aiuti A, Cattaneo F, Galimberti S, Benninghoff U, Cassani B, Callegaro L, et al. Gene therapy for immunodeficiency due to adenosine deaminase deficiency. NEJM. 2009;360(5):447-458. https://doi.org/10.1056/NEJMoa0805817

48. Carlucci F, Tabucchi A, Aiuti A, Rosi F, Floccari F, Pagani R, et al. Evaluation of ADA gene expression and transduction efficiency in ADA/SCID patients undergoing gene therapy. Nucleosides Nucleotides Nucleic Acids. 2004;23(8-9):12451248. https://doi.org/10.1081/NCN-200027508

49. Garcia-Perez $L$, van Eggermond $M$, van Roon $L$, Vloemans $S$, Cordes M, Schambach A, et al. Successful preclinical development of gene therapy for recombinase activating gene-1deficient SCID. Mol Ther Methods Clin Dev. 2020;17:666-682. https://doi.org/10.1016/j.omtm.2020.03.016

50. Van Til NP, Sarwari R, Visser TP, Hauer J, Lagresle-Peyrou C, Van Der Velden G, et al. Recombination-activating gene 1 (Rag1)-deficient mice with severe combined immunodeficiency treated with lentiviral gene therapy demonstrate autoimmune Omenn-like syndrome. J Allergy Clin Immunol. 2014;133(4):1116-1123. https://doi.org/10.1016/j. jaci.2013.10.009 